\title{
Auf dem Weg zum Glücklichsein
}

Exzerpt aus meinem neuen Buch - Auf dem Weg zum ICH entdecke ich das Glück (Teil 1). Von MMag. Ingrid Pirker-Binder ${ }^{2}$

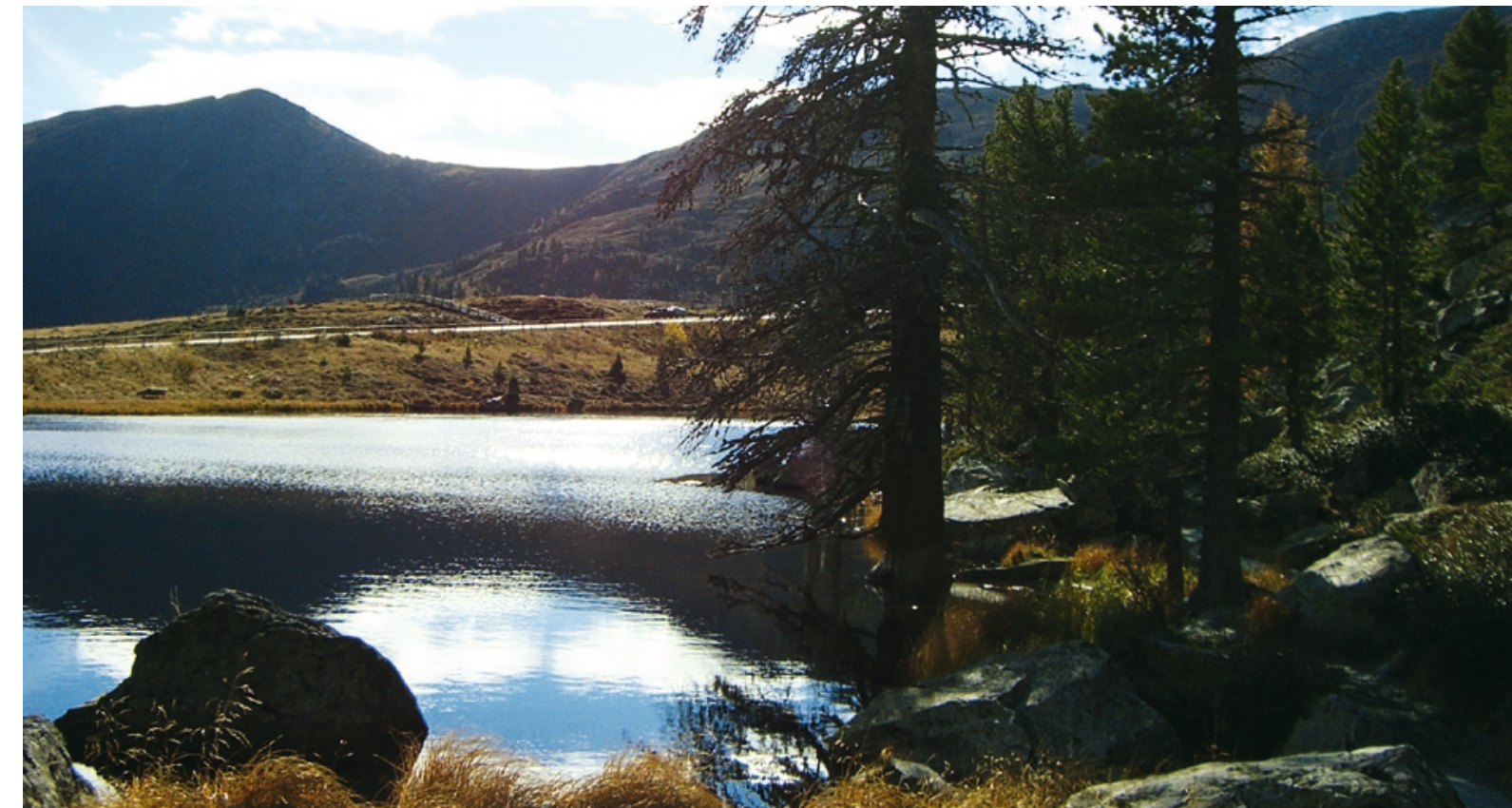

Was bedeutet eigentlich glücklich sein? Wo ist das Glück zu finden?

Einmal so richtig glücklich sein, ohne Sorgen, Probleme, Konflikte leben können, das wäre schön Träumen sie auch davon? Ertappen sie sich auch manchmal bei dem Gedanken, ,,das Leben könn te sooo schön sein, wenn nich dies oder das wäre, oder wenn dies oder das stattfinden würde, er das verändern konnte ... und so weiter". Die Reihe der Wünsche ist seh lang und hat immer den gleichen erstrebenswerten Inhalt: ES müsste oder sollte sich etwas ändern - alles Andere, nur nicht wir, dann wäre es perfekt.

Was bedeutet eigentlich glücklich sein? Wo ist das Glück zu finden? Wer und vor allem wie sind die Menschen, die es gefunden haben? Was haben sie gemacht, um es zu finden? Wie sieht der Weg zum Glück aus, oder wie könnte er aussehen? Oder besser gesagt, was steht denn unserem Glück im Weg?

\section{Der Weg}

„Wie erlangt man das Glück?" „Durch Erlernen, mit allem, was man erhält zufrieden zu sein“" "Dann kann man sich nie etwas wünschen“? „Doch, man kann", sagte der Meister, "vorausgesetzt, man tut dies in der Einstellung jenes ängstlichen Vaters, den ich einmal in einer Entbindungsanstalt traf. Als die
Hebamme sagte: „Sie haben sich bestimmt einen Jungen gewünscht, es ist aber ein Mädchen", erwiderte der Mann : Ach, das macht wirklich nichts, den ich habe mir ein Mädchen gewünscht, falls es kein Junge ist." (2)

In meiner Arbeit mit Menschen erarbeiten wir gemeinsam einzelne Wegstrecken, die uns unserer Bestimmung und damit dem Glücklichsein näher bringen können.

Auf alle Fälle hat es mit uns selbs zu tun, denn die Welt ist für alle gleich, was nicht heißt, dass sie für alle gleich komfortabel oder leichtlebig ist wie ein Paradies. Wenn wir in die Augen armer Straßenkinder in Afrik

\section{Fazit für die Praxis}

Es zahlt sich jedenfalls aus, den Glücksmomenten auf die Spur zu kommen, um diese Augenblicke bewusst und intensiv zu erleben und das, was LEBEN und GLÜCKLICHSEIN bedeutet, im ganzen Sein erspüren zu können. Sonst wäre es möglich, dass wir an der Essenz des Lebens vorübergehen, ohne sie zu bemerken. Welch' ein Verlust wäre das!

Nun, wo fangen wir am Nun, wo fangen wir ä besten LEIN Zu erspÜren? - Am und SEIN zu erspuren? - Am besten dort, wo alles beginn - bei uns selbst. blicken, kann uns aber Feuer entgegen leuchten, ein Lächeln und ein innere Ruhe treffen, die uns biswelen sprachlos macht. Wie ist es den möglich, dass diese Kinder, obwoh sie nichts besitzen, so fröhlich sein

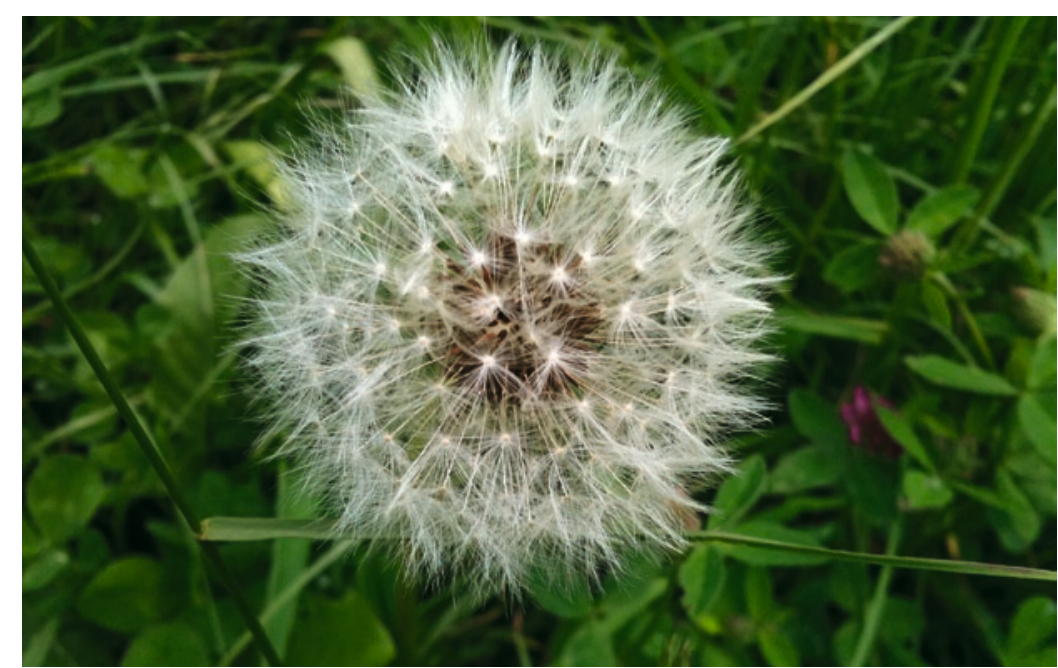

ben, obwohl wir diese oder jene Beschwerde oder Ängste haben, $o b$ wohl wir in diesem Leben nich wissen, warum uns etwas widerfährt, trotzdem ist es lebens- und liebenswert; es ist im Moment auch das einzige Leben, das jeder von uns jetzt besitzt. $\mathrm{Ob}$ wir noch an ein weiteres Leben denken können, wollen wir an späterer Stelle diskutieren

können, wie ist es möglich, dass sie trotzdem fröhlich sein können, obwohl sie in Armut leben.

\section{Trotzdem ...}

Da ist es, dieses Wort trotzdem, das mich seit meinem ersten Kontakt mit Viktor Frankls (3) Logotherapie und Existenzanalyse nicht mehr lo lässt. Sein Buch Trotzdem JA zum Leben (4) sagen hat Millionen be geistert. In meiner Arbeit als Psychotherapeutin und Coach komm dieses Wort sehr oft vor. Denn obses oder jenes Hindernis, diese oder jene Herausforde rung des Lebens vor uns liegen ha-
Stress- und Psychotherapeutin, Wien

De Mello A (2004): Wo das Glück zu finden ist; Weisheitsgeschichten für jeden Tag,

Frankl V, Lukas, E: Kurz gesagt - lang nachgedacht; Eine Zitatensammlung aus den

Schrittum V. Frankls und E. Lukas, Süd-

rotzdem JA ... schildert wie er das KZ

überlebt hat

Korrespondenz:
MMag. Ingrid Pirker-Binder

MMag. Ingrid Pi
c/o Institut BiCO

Institut für Biofeedback

Schopenhauerstraße 39/2/9
1180 Wien

Tel.: 0676/70 47668

E-Mail: stress@pirker-binder.a

\section{Lymphomyosot $^{\circledR}$ \\ Tabletten und Tropfen}

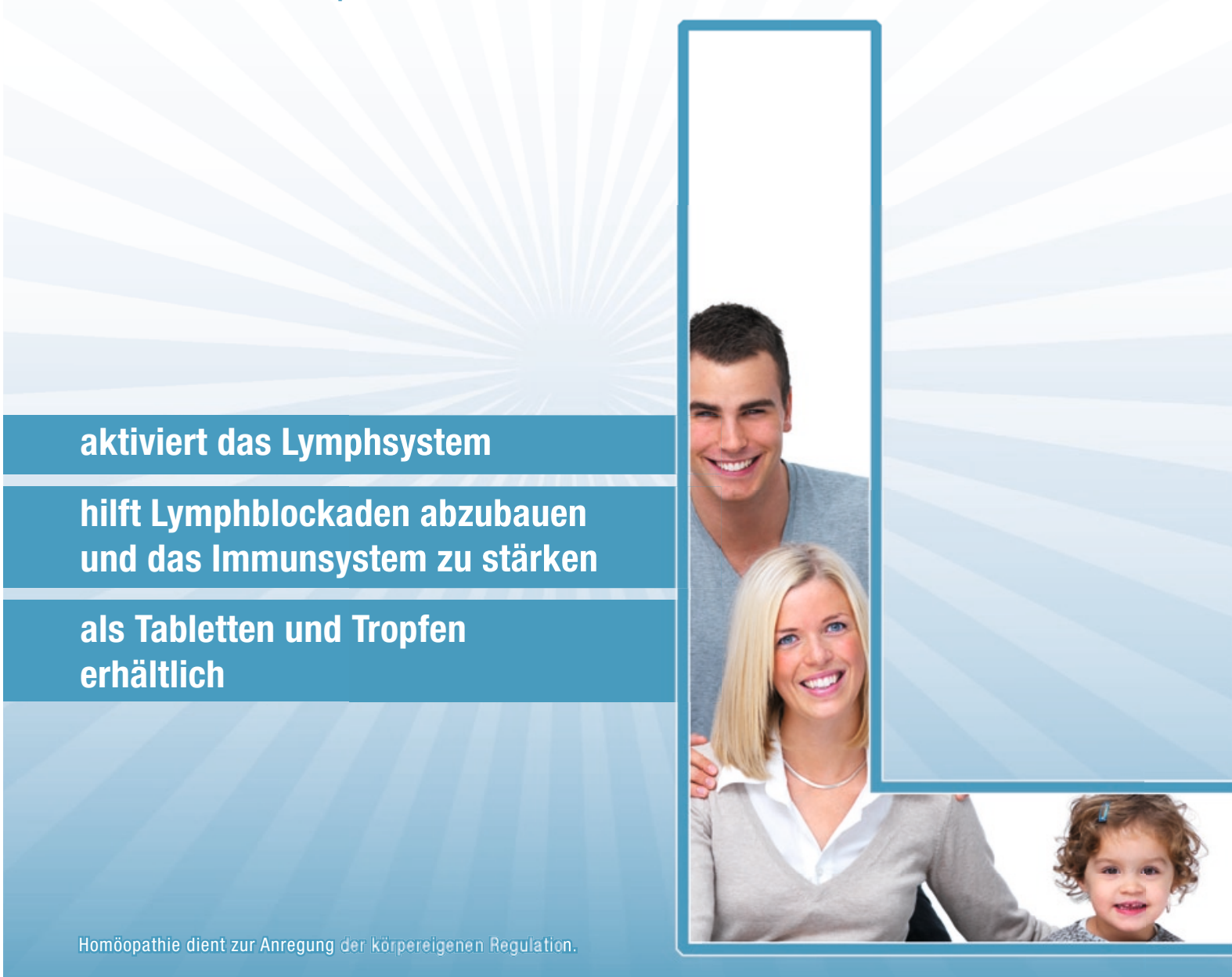

Auf alle Fälle hat es mit uns selbst zu tun, denn die Welt ist für alle gleich. 